\title{
TOX3 protein expression is correlated with pathological characteristics in breast cancer
}

\author{
CUI-CUI HAN ${ }^{*}$, LI-LING YUE*, YING YANG, BAI-YU JIAN, LI-WEI MA and JI-CHENG LIU \\ Institute of Medicine, Qiqihar Medical University, Qiqihar, Heilongjiang 161042, P.R. China
}

Received December 17, 2014; Accepted December 23, 2015

DOI: $10.3892 / \mathrm{ol} .2016 .4117$

\begin{abstract}
TOX3 is a newly identified gene that has been observed to correlate with breast cancer by genome-wide association studies (GWAS) in recent years. In addition, it has been noted that single-nucleotide polymorphisms (SNPs) in the TOX3 gene have a strong correlation with estrogen receptor (ER)-positive tumors. However, the role of TOX3 in breast carcinoma development is still unclear. There are limited studies on the subject of TOX3 mRNA expression in breast tumors and little information on the variation of TOX 3 protein expression in relation to the clinical pathological features in breast cancer and healthy tissues. In this study, we characterize the protein expression of TOX3 in breast tumors with respect to various clinical and pathological characteristics and explore the correlation between TOX3 protein expression and ER-positive tumors. A breast cancer tissue microarray containing 267 human breast tumors and 25 healthy controls, breast cancer cell lines (ZR-75-1, MDA-MB-231, MCF-7 and Bcap-37) with positive or negative ER expression, tumor tissues and matched controls were used to analyze the protein expression levels of TOX3 by immunohistochemistry, western blot analysis and quantitative polymerase chain reaction. Among the 267 breast tumor specimens, ER expression was detected in 66 tumor tissues. The expression levels of TOX3 increased in breast carcinoma tissue compared with controls, and were higher in advanced carcinoma (T3 and T4), lymph node metastases tissues (N2) and stage III tissues. Furthermore, TOX3 protein expression was more intense in ER-positive tumors, but did not demonstrate a statistical significance. However, it was significantly increased in ER-positive breast cancer cell lines (ZR-75-1, MCF-7 and Bcap-37) compared with the MDA-MB-231 cell line, which had ER-negative expression. Our findings provide support to the hypothesis that TOX3 has
\end{abstract}

Correspondence to: Professor Ji-Cheng Liu, Institute of Medicine, Qiqihar Medical Univeristy, 333 Bukui Street, Jianhua, Qiqihar, Heilongjiang 161042, P.R. China

E-mail: qyybliu@sohu.com

*Contributed equally

Key words: TOX3, breast cancer, estrogen receptor a strong correlation with the development of breast cancer. The current study is likely to assist in investigating the mechanisms involved in breast cancer development.

\section{Introduction}

Breast cancer has become the leading cause of mortality in females and it is a significant threat to the health of females (1). It is believed that breast carcinoma is a heterogeneous disease with genetic and non-genetic etiology (2). To date, it has been confirmed that breast cancer susceptibility genes include breast cancer 1 (BRCA1) and BRCA2. However, these genes only account for 5 to $10 \%$ of cases with inherited mutations, and the majority of breast cancers are sporadic $(3,4)$. Previous genome-wide association studies (GWAS) involving a large number of samples have revealed novel single-nucleotide polymorphisms (SNPs) of breast cancer. They are respectively located on genes FGFR2, TNRC9/TOX3, MAP3K1, LSP1 and CASP8 (5). Among these, TOX high mobility group box family member 3 (TOX3) has been further confirmed to have a stronger association with the risk of breast cancer by GWAS studies in different people (6-13).

TOX3 is a member of a high mobility group (HMG) of box proteins that is associated with the regulation of thymocyte selection (14), and is also called trinucleotide repeat-containing gene 9 (TNRC9) or CAG trinucleotide repeat-containing gene F9 (CAGF9) (15). Structurally, TOX3 is a nucleoprotein which includes a nuclear localization signal in the N-terminal domain, a HMG box domain which is able to change the chromatin structure by bending and unwinding DNA, and a C-terminal polyglutamine stretch. It is located on chromosome 16q12.1 (16). Its structure suggests that it may be closely associated with transcription. TOX3 is identified as a novel regulator of calcium-dependent transcription and interacts with the CREB-CBP complex to regulate CRE-mediated transcription in rat neuronal cells (17). Dittmer et al observed that overexpression of TOX3 protects neuronal cells from cell death by inducting anti-apoptotic transcripts and inhibiting pro-apoptotic transcripts; it depends on the phosphorylated CREB or CITED1 within the transcriptionally active complex interacting with the native CREB and inducing the CREB-responsive BCL-2 promoter (18). Furthermore, there are certain studies demonstrating that TOX3 is correlated with other carcinomas (19-21). A study by Birkenkamp-Demtroder et al revealed that TOX3 overexpression 
in bladder cancer cells reduces cell proliferation and affects the interferon signaling pathway (15). In addition, TOX3 expression was observed to be notably upregulated in lung adenocarcinoma compared with control tissues (20). However, there is increasing evidence demonstrating that TOX3 is closely correlated with the risk of breast cancer. Fasching et al reported that TOX3 was associated with overall survival in breast carcinoma (22).

The expression level of TOX3 in breast cancer remains unclear. There is evidence that high mRNA expression levels of TOX3 occur in patients with shorter overall survival, and a positive correlation has been observed between the mRNA expression level of TOX3 and breast carcinomas with metastasis (23). However, a study by Riaz et al indicated that the risk alleles (rs3803662 and rs12443621) were associated with lower expression of TOX 3 mRNA and suggested a tumor suppressor role of TOX3 (24). Additionally, susceptibility loci in TOX3 had a stronger association with ER-positive breast cancer than ER-negative breast cancer $(8,25)$. However, the mRNA expression level does not represent protein function. It is unclear whether TOX3 is involved in breast cancer tumorigenesis or ER-positive breast cancer, and therefore it is critical to understand the expression levels of TOX3 protein in human breast carcinoma and controls. Few studies have investigated TOX3 protein expression in a large number of samples in relation to clinicopathological characteristics. The aim of the present study was to measure the expression of TOX3 protein in breast cancer, controls and ER-positive or negative carcinoma, to check whether TOX3 demonstrated an association with clinicopathological characteristics of patients and tumors, and to provide a comprehensive evaluation for TOX3 in breast cancer tumorigenesis.

\section{Materials and methods}

Human tissue samples. A breast cancer tissue microarray purchased from US Biomax (Rockville, MD, USA) were used to assess TOX3 protein expression with immunohistochemical staining. It contained 267 human breast cancer tissue samples (comprising 217 invasive ductal carcinomas, 45 invasive lobular carcinoma, 2 medullary carcinoma, 2 mucinous carcinomas and 1 invasive papillary carcinoma) and 25 healthy controls. The age of tumor patients ranged from 27 to 82 years with a mean age of 49.3 years, and the age of controls ranged from 15 to 50 years with an average age of 30.2 years. The pathological information of patients is shown in Table I. The expression of ER was assessed in 66 tumor patients, and there were noted to be 22 ER-positive patients and 44 ER-negative cases. Additionally, three fresh breast cancer tissues and matched controls used to detect TOX3 expression by western blot analysis and quantitative polymerase chain reaction (qPCR) were obtained from the Affiliated Hospital of Qiqihar Medical University, China. The use of these samples for this study was approved by the ethics committee of Qiqihar Medical University, and the written informed consent was obtained from the subjects.

Cell culture. Human breast cancer cell lines (ZR-75-1, MDA-MB-231, MCF-7 and Bcap-37) with ER-positive or negative expression were purchased from the Cell Bank of the Chinese Academy of Sciences (Shanghai, China). ZR-75-1 and Bcap-37 cells were maintained in Roswell Park Memorial Institute-1640 (RPMI-1640) medium, and MDA-MB-231 cells were cultured in Leibovitz's-15 (L15) medium. MCF-7 cells were maintained in minimum essential medium (MEM). The media were supplemented with $10 \%$ fetal bovine serum (FBS), penicillin $(100 \mathrm{IU} / \mathrm{ml})$ and streptomycin $(100 \mu \mathrm{g} / \mathrm{ml})$. In addition to the aforementioned items, the RPMI-1640 medium used for ZR-75-1 cells included glucose $(2.5 \mathrm{~g} / \mathrm{l})$ and sodium pyruvate $(0.11 \mathrm{~g} / \mathrm{l})$ and MEM medium used for MCF-7 cells contained sodium pyruvate $(0.11 \mathrm{~g} / \mathrm{l})$ and bovine insulin $(0.01 \mathrm{mg} / \mathrm{ml})$. ZR-75-1, MCF-7 and Bcap-37 cells were incubated in a $5 \% \mathrm{CO}_{2}$ humidified incubator at $37^{\circ} \mathrm{C}$ and MDA-MB-231 cells were cultured at $37^{\circ} \mathrm{C}$ in a humidified atmosphere of $100 \%$ air.

Immunohistochemistry. Immunohistochemistry was performed to analyze the protein expression of TOX3. The tissue microarray section was pretreated at $60^{\circ} \mathrm{C}$ for $1 \mathrm{~h}$, then dewaxed and rehydrated by xylene and graded alcohol. Antigen retrieval was facilitated in sodium citrate buffer for $2 \mathrm{~min}$ in an autoclave at $121^{\circ} \mathrm{C}$. Endogenous peroxidase activity was blocked with $3 \%$ hydrogen peroxide/methanol for $10 \mathrm{~min}$ at room temperature. Thereafter, the section was incubated with goat serum for $10 \mathrm{~min}$ at room temperature and then with TOX3 rabbit polyclonal antibody diluted at 1:80 (Abgent, San Diego, CA, USA) at $4^{\circ} \mathrm{C}$ overnight. Staining was implemented with an UltraSensitive $^{\mathrm{TM}}$ SP IHC kit (Fuzhou Maixin Biotech, Fujian, China) according to the manufacturer's instructions. Finally, the section was stained with 3,3'-diaminobenzidine as the chromogen and counterstained with hematoxylin.

TOX3 expression was estimated semiquantitatively according to the TOX3-immunopositive cell percentage in tumor cells ( 0 , negative staining; $1,0-10 \%$ positive; $2,11-50 \%$ positive; 3 , $51-80 \%$ positive; 4 , $80-100 \%$ positive) (26). Secondly, the staining intensity of positive cells was scored as follows: 0 , negative; 1 , faint; 2 , moderate; 3 , strong. On the basis of these data, the results were further scored 0-3 (the percentage of positive cells multiplied by the staining intensity score, resulting in a score from 0 to 12 ; a score of 0 or 1 was considered as negative, and 2-3 was considered as $1+, 4-7$ as $2+$, and 8-12 as 3+) (27). The results were analyzed by two pathologists respectively who were blinded to the clinicopathological information.

$q P C R$. Total RNA was extracted from cells or fresh tumor tissues with RNAiso reagent (Takara Biotechnology, Dalian, China). cDNA was synthesized using a PrimeScript ${ }^{\mathrm{TM}}$ RT reagent kit (Takara Biotechnology) according to the manufacturer's instructions. The qPCR reaction was performed with a SYBR Premix Ex Taq ${ }^{\mathrm{TM}}$ (Tli RNaseH Plus) kit (Takara Biotechnology) in a final reaction volume of $50 \mu \mathrm{l}$ containing 2X SYBR Premix Ex Taq ${ }^{\mathrm{TM}}$ (Tli RNaseH Plus) (Takara Biotechnology), ROX reference dye and the corresponding primers. The PCR conditions were as follows: 1 cycle of $30 \mathrm{sec}$ at $95^{\circ} \mathrm{C}, 40$ cycles of $5 \mathrm{sec}$ at $95^{\circ} \mathrm{C}$, and $31 \mathrm{sec}$ at $60^{\circ} \mathrm{C}$. The PCR reaction was implemented in an Applied Biosystems 7300 Real-Time PCR system (Applied Biosystems, Foster City, CA, USA). $\beta$-actin was used as the internal control. The sequences of following primers were used for the qPCR reaction: 5'-CTG GGA CGA CAT GGA GAA AA-3' (sense) and 
Table I. Pathological information of patients.

Pathological variables Number of patients

Normal breast tissues 25

Breast cancer tissues 267

TNM grading

T1/T2/T3/T4

$32 / 190 / 27 / 18$

Lymph node metastasis

N0/N1/N2/N3

$210 / 48 / 8 / 1$

TNM stage

I/II/III/IV

$31 / 209 / 24 / 3$

Estrogen receptor

$\mathrm{ER}^{+} / \mathrm{ER}^{-}$

$22 / 44$

TNM, tumor-node-metastasis.

5'-AAG GAA GGC TGG AAG AGT GC-3' (antisense) for the $\beta$-actin gene; 5'-TAT GCC TCA CAC ATC TCC TTC A-3' (sense) and 5'-ATG GCT CTG TTG GCT TCA TC-3' (antisense) for the TOX3 gene. The qPCR analysis was performed using the $2^{-\Delta \Delta C t}$ method (28). The experiments were implemented in triplicate to ensure reproducibility.

Western blot. Western blot analysis was performed to detect the protein expression of TOX 3 in breast tumor, corresponding control tissue and breast cancer cell lines. Proteins were isolated with RIPA lysis buffer (Beyotime Biotechnology, Haimen, China) from tissue specimens. The protein concentration was detected quantitatively using a bicinchoninic acid protein assay kit (Beijing ComWin Biotech, Beijing, China). Protein supernatant was added to lane marker loading buffer and boiled at $100^{\circ} \mathrm{C}$ for $5 \mathrm{~min}$. Furthermore, the proteins were separated by $10 \%$ sodium dodecyl sulfate polyacrylamide gel electrophoresis and then transferred to nitrocellulose membrane by electrophoresis, and nonspecific protein bindings were blocked with blocking buffer at $4^{\circ} \mathrm{C}$ overnight. Subsequently, the membranes were incubated with TOX3 rabbit monoclonal antibody (1:1200; Abcam, Cambridge, UK) and GAPDH mouse polyclonal antibody (1:3000; Beijing ComWin Biotech, Beijing, China) for $3 \mathrm{~h}$ at room temperature and washed with Tris-buffered saline with $0.1 \%$ Tween-20 (TBST) three times. Next, they were incubated with IgG secondary antibody (1:3000; Cell Signaling Technology, MA, USA) for $2 \mathrm{~h}$ at room temperature and washed again with TBST three times. Finally, the blots were developed using a SuperSignal West Pico substrate kit (Thermo Fisher Scientific, MA, USA). GAPDH was used as the internal control to measure the relative expression of TOX3. Band intensities were determined using Image J2x software version 2.1.4.7 (National Institutes of Health, MD, USA).

Statistical analysis. The results from qPCR and western blot analysis were expressed as the means \pm standard deviation and assessed using Student's t-test. Pearson's $\chi^{2}$ test and the Wilcoxon rank test were used to analyze categorical associations. $\mathrm{P}<0.05$ was considered to indicate a statistically

A
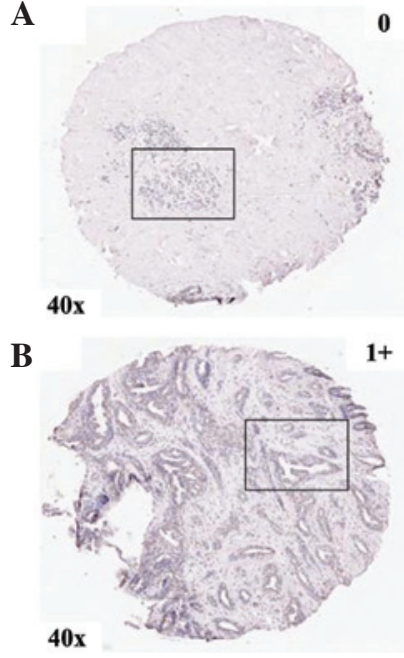

C

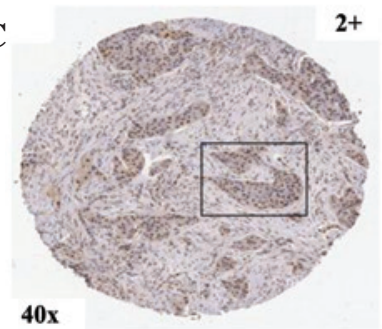

$2+$

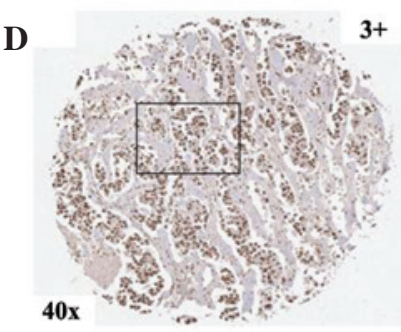

E

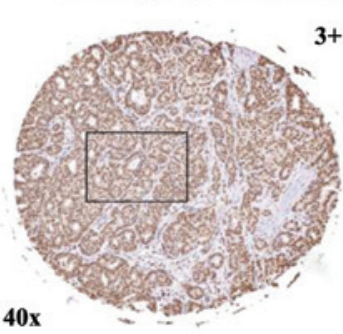

$3+$
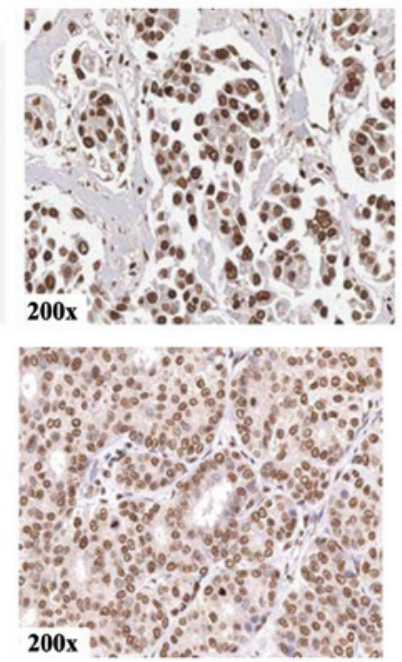

Figure 1. Protein expression of TOX3 in human control breast tissues and breast carcinomas in association with pathological characteristics. The representative tissue scores for control breast tissues (A, score 0 ) and tumor-node-metastasis grading of breast carcinoma (B, T1 stage, 1+score; C, T2 stage, score 2+; D, T3 stage, score 3+; E, T4 stage, score 3+) are given. The left panels reveal the immunohistochemistry staining at $40 \mathrm{x}$ magnification and the right panels at 200x magnification. As shown, the protein expression of TOX3 was upregulated in breast carcinoma, and was particularly higher in T3 and T4 stage than in T1 stage.

significant difference. All the analyses were performed using SPSS 17.0 software (SPSS Inc., Chicago, IL, USA).

\section{Results}

Expression of TOX3 is increased in breast tumor tissue compared with controls. In this study, immunohistochemistry was used to detect the protein expression of TOX3 in tissue microarray samples consisting of 25 control breast tissues and 
Table II. Expression of TOX3 protein in human breast tumors and controls.

\begin{tabular}{|c|c|c|c|}
\hline Tumor pathology & Number of patients (n) & Immunoreactive score (mean) & P-value \\
\hline Normal breast tissues & 25 & 0.88 & \\
\hline Breast cancer tissues & 267 & 1.98 & $<0.010$ \\
\hline \multicolumn{4}{|l|}{ TNM grading } \\
\hline $\mathrm{T} 1$ & 32 & 1.69 & \\
\hline $\mathrm{T} 2$ & 190 & 1.93 & 0.059 \\
\hline $\mathrm{T} 3$ & 27 & 2.30 & 0.020 \\
\hline $\mathrm{T} 4$ & 18 & 2.56 & $<0.010$ \\
\hline \multicolumn{4}{|l|}{ Lymph node metastasis } \\
\hline No & 210 & 1.94 & \\
\hline N1 & 48 & 2.10 & 0.143 \\
\hline $\mathrm{N} 2$ & 8 & 2.63 & 0.006 \\
\hline N3 & 1 & 3.00 & 0.132 \\
\hline \multicolumn{4}{|l|}{ TNM stage } \\
\hline I & 31 & 1.68 & \\
\hline II & 209 & 1.97 & 0.030 \\
\hline III & 24 & 2.54 & $<0.010$ \\
\hline IV & 3 & 2.67 & 0.049 \\
\hline
\end{tabular}

TNM, tumor-node-metastasis.

Table III. TOX3 expression in breast carcinoma with respect to various pathological characteristics.

\begin{tabular}{|c|c|c|c|c|c|}
\hline \multirow[b]{2}{*}{ Tumor pathology } & \multicolumn{3}{|c|}{ TOX3 expression } & \multirow[b]{2}{*}{ Total (n) } & \multirow[b]{2}{*}{ P-value } \\
\hline & $1+[\mathrm{n}(\%)]$ & $2+[\mathrm{n}(\%)]$ & $3+[\mathrm{n}(\%)]$ & & \\
\hline TNM grading & & & & & $<0.01$ \\
\hline $\mathrm{T} 1$ & $14(43.75)$ & $14(43.75)$ & $4(12.5)$ & 32 & \\
\hline $\mathrm{T} 2$ & $51(26.84)$ & $101(53.16)$ & $38(20.00)$ & 190 & \\
\hline $\mathrm{T} 3$ & $4(14.82)$ & $11(40.74)$ & $12(44.44)$ & 27 & \\
\hline $\mathrm{T} 4$ & $0(0.00)$ & $8(44.44)$ & $10(55.56)$ & 18 & \\
\hline Lymph node metastasis & & & & & 0.03 \\
\hline No & $56(26.67)$ & $111(52.86)$ & $43(20.48)$ & 210 & \\
\hline N1 & $11(22.92)$ & $21(43.75)$ & $16(33.33)$ & 48 & \\
\hline $\mathrm{N} 2$ & $0(0.00)$ & $3(37.50)$ & $5(62.50)$ & 8 & \\
\hline N3 & $0(0.00)$ & $0(0.00)$ & $1(100.00)$ & 1 & \\
\hline TNM stage & & & & & $<0.01$ \\
\hline I & $14(45.16)$ & $13(41.94)$ & $4(12.90)$ & 31 & \\
\hline II & $54(25.84)$ & $108(51.67)$ & $47(22.49)$ & 209 & \\
\hline III & $0(0.00)$ & $11(45.83)$ & $13(54.17)$ & 24 & \\
\hline IV & $0(0.00)$ & $1(33.33)$ & $2(66.67)$ & 3 & \\
\hline
\end{tabular}

TNM, tumor-node-metastasis.

267 breast carcinoma tissue specimens. The mean immunoreactive score (IRS) of TOX3 in breast carcinoma tissue was notably higher than that in controls (Table II). Additionally, the levels of TOX3 expression in breast carcinoma demonstrated a positive correlation with the grading and staging of breast tumors. High TOX3 expression levels were noted in advanced stages (T3 and T4). In addition, the mean IRS of TOX3 in stage T3 and T4 was significantly increased compared with that in stage T1 (Table II). Furthermore, compared with T1 stage, the percentage of TOX3 high expression (IRS=3+) in T3 and T4 stages was notably increased (Table III, Fig. 1). The levels of TOX3 expression in tumors with lymph node metastasis (N2 
Table IV. Protein expression of TOX3 in estrogen receptor-positive tumors.

\begin{tabular}{lccc}
\hline $\begin{array}{l}\text { Estrogen } \\
\text { receptor }\end{array}$ & $\begin{array}{c}\text { Number of } \\
\text { patients (n) }\end{array}$ & $\begin{array}{c}\text { Immunoreactive } \\
\text { score (mean) }\end{array}$ & P-value \\
\hline ER $^{-}$ & 44 & 2.07 & \\
ER $^{+}$ & 22 & 2.36 & 0.157 \\
\hline
\end{tabular}
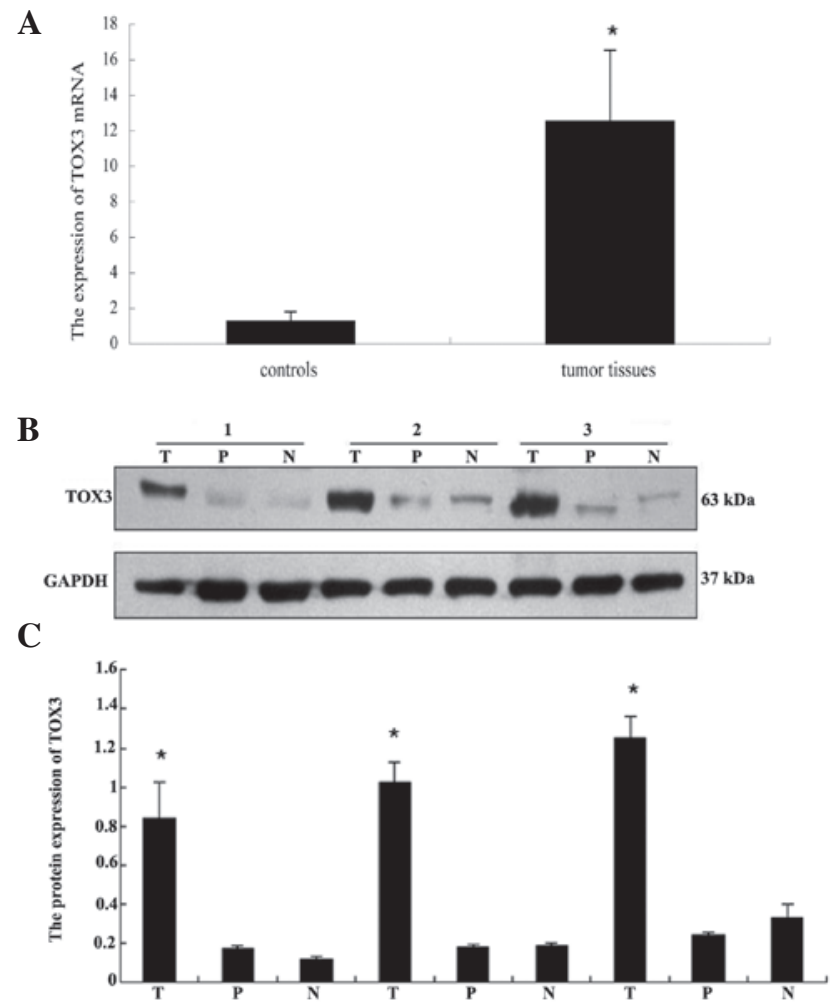

Figure 2. Expression of TOX3 in tumor tissues and matched controls. The mRNA and protein expression of TOX3 was tested in breast cancer tissues using quantitative polymerase chain reaction (A) and western blot analysis (B) in fresh matched control tissues. The results demonstrate that the TOX3 protein level of the three breast cancer patients in tumor tissues (T) were higher compared with matched para-carcinoma tissues $(\mathrm{P})$ and healthy control breast tissues (N). (C) Relative expression of TOX3 after normalizing with GAPDH. "P<0.05 vs. control tissues.

stage) were significantly higher than those without regional lymph node metastasis (N0 stage), but there was no statistical significance in N3 stage (Table III). Moreover, high TOX3 expression in stage III and IV was also observed (Table III). To further confirm the results of immunohistochemistry, qPCR and western blot analysis were implemented to detect the expression of TOX $3 \mathrm{mRNA}$ and protein in the fresh tissues. Total RNA was obtained from breast carcinoma tissues and matched control breast tissue of three patients. As shown in Fig. 2, compared with the matched adjacent control breast tissue, the expression levels of TOX 3 mRNA were upregulated significantly in breast cancer specimens $(\mathrm{P}<0.05$; Fig. $2 \mathrm{~A})$. The western blot analysis results further confirmed the increased expression of TOX3 in breast malignancies compared with controls ( $\mathrm{P}<0.05$; Fig. 2B and $\mathrm{C})$. These results were consistent with the immunohistochemistry results.

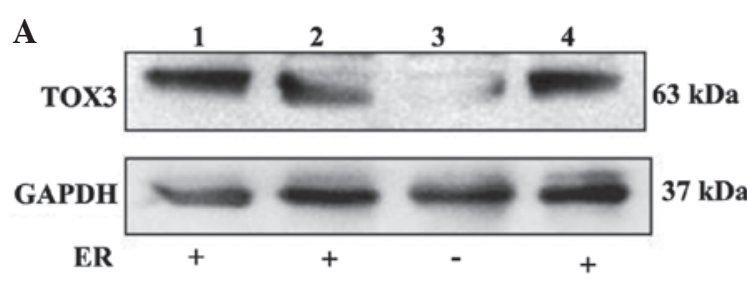

B

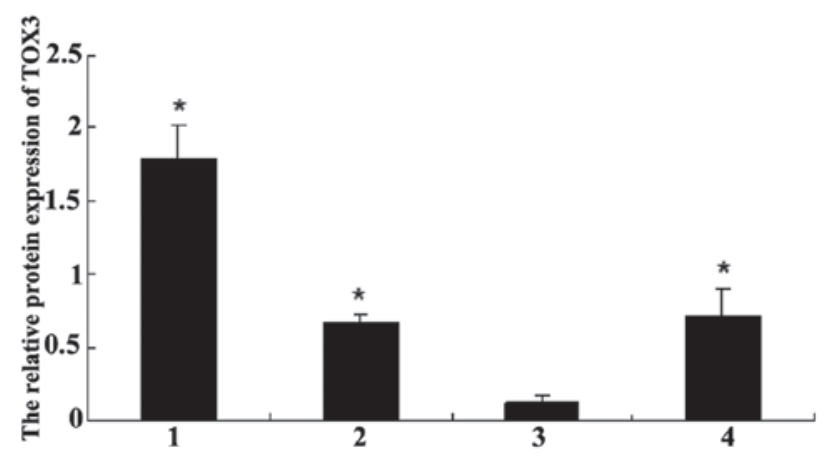

Figure 3. Expression of TOX3 in breast cancer lines. (A) The expression of TOX3 in ER-positive and ER-negative breast cancer lines. The expression of TOX3 was upregulated in ZR-75-1 (1), MCF-7 (4) and Bcap-37 (2) cell lines which had ER-positive expression in contrast to ER-negative cell line MDA-MB-231 (3). (B) The relative expression of TOX3 in breast cancer lines after normalizing with GAPDH. "P<0.05 vs. MDA-MB-231 cell line.

Protein expression of TOX3 in ER-positive tumor and breast cancer cells. As shown from the immunohistochemical staining results, the IRS of TOX3 protein expression was higher in ER-positive tumor than in ER-negative tissue, but there was no statistical significance (Table IV). Conversely, a high degree of diversity of TOX3 protein expression was noted in breast cancer cells, which was intense in ZR-75-1, MCF-7 and Bcap-37 cell lines compared with MDA-MB-231 breast cell lines (Fig. 3). Notably, the ER demonstrated positive expression in ZR-75-1, MCF-7 and Bcap-37 cell lines, while the MDA-MB-231 cell line had ER-negative expression.

\section{Discussion}

In recent years, evidence from GWAS has demonstrated that TOX3 has a strong association with the risk of breast cancer. Certain studies suggest that the TOX3 gene is associated with mammographic density (29), and that breast cancer patients who express high TOX3 mRNA levels have shorter overall survival and distant metastasis-free survival times (23). One study reveals an association between the risk alleles (rs3803662 and rs12443621) and lower expression of TOX3 mRNA (24), but another study demonstrates high mRNA expression levels of TOX3 in patients with affected lymph nodes (23). It remains unclear whether these diverse results were caused by differences in the individuals involved or solely by methodical differences. Differential TOX3 expression may indicate a diverse progression step during tumor transformation, and the expression of mRNA may not be in agreement with that of protein. Therefore, given the lack of data on the protein expression of TOX3 in malignant breast tumors, in the present study we assessed the protein expression levels of TOX3 in breast tumor samples and controls using immunohistochemistry. 
Moreover, western blot analysis and qPCR were performed to further confirm the immunohistochemistry results in three breast tumor tissues and matched controls in order to demonstrate the clinical pathological value of TOX3.

Our data suggest that the protein expression levels of TOX3 in breast carcinoma specimens were significantly higher than those in controls. Western blot analysis and qPCR results from fresh tissues further confirmed these results. Moreover, differential protein expression levels of TOX3 were noted depending on the TNM stage and the presence of lymph node metastases. TOX3 was upregulated significantly in T3 and T4 stages compared with T1 stage. Compared with patients with no lymph node metastases (N0), high expression of TOX3 was observed in patients with lymph node metastases (N2) and stage III disease, but there was no statistical significance in N3 stage patients. This may be due to the fact that there was only one case in the N3 stage. Analysis of the literature in 32 tumor samples also revealed that TOX3 expression was higher in advanced breast carcinoma (T3 and T4 stages) than in local breast cancer (T1 and T2 stages) (30), but this study did not demonstrate the association of TOX3 with lymph node metastases and degree of differentiation. In addition, another study revealed that high mRNA expression levels of TOX3 were observed in lymph node patients and that this was associated with survival (23). These results are compatible with those of Smid et al, who reported that the TOX3 gene was implicated in breast carcinoma metastasis to the bone (31). Results from an analysis by Shan et al demonstrated increased expression of TOX3 in MDA-MB-231 cells, which conferred a stronger capability for invasion and metastasis. The study also proposed that the TOX3 gene promoted breast cancer aggressiveness and that TOX3 gene amplification is significantly associated with a reduction in disease-free and metastasis-free survival rates (30). Data from the present study indicate that TOX3 is associated with clinical and pathological characteristics of the resulting invasive breast malignancy. It may also be involved in the progression of breast cancer and be associated with poor prognosis in breast cancer patients.

In addition, certain researchers suggested that TOX3 was strongly associated with ER-positive cancers by GWAS $(6,8,24,25)$. These studies are consistent with the finding that, compared with ER-negative tumors, mRNA expression levels of TOX3 are significantly higher in ER-positive carcinomas (23). Additionally, there are studies confirming that the TOX3 transcript was increased in luminal A and luminal B breast cancer subtypes, but was downregulated in basal-like breast cancer (32). It is of note that luminal A and luminal B breast cancers are ER-positive carcinomas, while the basal-like breast cancer subtype is an ER-negative tumor (33). However, there are no data on the protein expression of TOX3 in ER-positive carcinomas. In the present study, high protein expression levels of TOX3 were noted in ER-positive cancerous specimens compared with ER-negative carcinomas, but there was no obvious statistical significance. This is may be due to the limited number of cases in the analyses, and it is necessary to increase the number of cases to further investigate the association between TOX3 expression and ER expression in breast carcinoma. Conversely, the protein expression level of TOX3 is significantly reduced in MDA-MB-231 cells, while it is intense in ZR-75-1, MCF-7 and Bcap-37 cells. It is notable that ER expression is negative in the MDA-MB-231 cell line, but positive in ZR-75-1, MCF-7 and Bcap-37 cells. This study demonstrates that TOX3 may be correlated with the risk of breast cancer, particularly ER-positive cancers. Our study further supports the link between TOX3 and ER-dependent transcription. However, it is necessary to further study this subject to confirm these findings.

In conclusion, our study provides an insight into the protein expression levels of TOX3 in breast carcinoma and controls. It reveals that protein expression of TOX3 is upregulated in breast carcinoma and differs depending on various pathological characteristics. It may be correlated with the risk of breast cancer; specifically, TOX3 expression may be correlated with ER-positive tumors. Our data may lay the foundation for gaining further insight into the potential regulation and function of TOX3 during breast cancer development.

\section{Acknowledgements}

This study was supported by the National Natural Science Foundation of China (no. 81374021 and 81202084), the Key Project Research Fund of Qiqihar Medical University (no. QY2013ZD-02) and the Science and Technology Program of Qiqihar (SFGG-201201).

\section{References}

1. Ferlay J, Shin HR, Bray F, Forman D, Mathers C and Parkin DM: Estimates of worldwide burden of cancer in 2008: GLOBOCAN 2008. Int J Cancer 127: 2893-2917, 2010.

2. Dapic V, Carvalho MA and Monteiro AN: Breast cancer susceptibility and the DNA damage response. Cancer Control 12: 127-136, 2005.

3. Di LJ, Fernandez AG, De Siervi A, Longo DL and Gardner K: Transcriptional regulation of BRCA1 expression by a metabolic switch. Nat Struct Mol Biol 17: 1406-1413, 2010.

4. Prosperi MC, Ingham SL, Howell A, Lalloo F, Buchan IE and Evans DG: Can multiple SNP testing in BRCA2 and BRCA1 female carriers be used to improve risk prediction models in conjunction with clinical assessment? BMC Med Inform Decis Mak 14: 87, 2014.

5. Easton DF, Pooley KA, Dunning AM, Pharoah PD, Thompson D, Ballinger DG, Struewing JP, Morrison J, Field H, Luben R, et al: Genome-wide association study identifies novel breast cancer susceptibility loci. Nature 447: 1087-1093, 2007.

6. Stacey SN, Manolescu A, Sulem P, Rafnar T, Gudmundsson J, Gudjonsson SA, Masson G, Jakobsdottir M, Thorlacius S, Helgason A, et al: Common variants on chromosomes 2q35 and $16 \mathrm{q} 12$ confer susceptibility to estrogen receptor-positive breast cancer. Nat Genet 39: 865-869, 2007.

7. Ruiz-Narváez EA, Rosenberg L, Cozier YC, Cupples LA, Adams-Campbell LL and Palmer JR: Polymorphisms in the TOX3/LOC643714 locus and risk of breast cancer in African-American women. Cancer Epidemiol Biomarkers Prev 19: 1320-1327, 2010.

8. Liang J, Chen P, Hu Z, Shen H, Wang F, Chen L, Li M, Tang J, Wang $\mathrm{H}$ and Shen $\mathrm{H}$ : Genetic variants in trinucleotide repeat-containing 9 (TNRC9) are associated with risk of estrogen receptor positive breast cancer in a Chinese population. Breast Cancer Res Treat 124: 237-241, 2010.

9. Chen MB, Wu XY, Shen W, Wei MX, Li C, Cai B, Tao GQ and Lu PH: Association between polymorphisms of trinucleotide repeat containing 9 gene and breast cancer risk: evidence from 62,005 subjects. Breast Cancer Res Treat 126: 177-183, 2011.

10. Han W, Woo JH, Yu JH, Lee MJ, Moon HG, Kang D and Noh DY: Common genetic variants associated with breast cancer in Korean women and differential susceptibility according to intrinsic subtype. Cancer Epidemiol Biomarkers Prev 20: 793-798, 2011. 
11. Elematore I, Gonzalez-Hormazabal P, Reyes JM, Blanco R, Bravo T, Peralta O, Gomez F, Waugh E, Margarit S, Ibañez $G$, et al: Association of genetic variants at TOX3, $2 \mathrm{q} 35$ and $8 \mathrm{q} 24$ with the risk of familial and early-onset breast cancer in a South-American population. Mol Biol Rep 41: 3715-3722, 2014.

12. Long J, Cai Q, Shu XO, Qu S, Li C, Zheng Y, Gu K, Wang W, Xiang YB, Cheng $\mathrm{J}$, et al: Identification of a functional genetic variant at $16 \mathrm{q} 12.1$ for breast cancer risk: results from the Asia Breast Cancer Consortium. PLoS Genet 6: e1001002, 2010.

13. He X, Yao G, Li F, Li M and Yang X: Risk-association of five SNPs in TOX3/LOC643714 with breast cancer in southern China. Int J Mol Sci 15: 2130-2141, 2014.

14. Wilkinson B, Chen JY, Han P, Rufner KM, Goularte OD and Kaye J: TOX: an HMG box protein implicated in the regulation of thymocyte selection. Nat Immunol 3: 272-280, 2002.

15. Birkenkamp-Demtroder K, Mansilla F, Dyrskjøt L, Thorsen K, Fristrup N, Brems-Eskildsen AS, Munksgaard PP, Sørensen KD, Borre $\mathrm{M}$ and $\varnothing$ rntoft TF: TOX3 (TNRC9) over expression in bladder cancer cells decreases cellular proliferation and triggers an interferon-like response. J Mol Biomark Diagn 4: 2,2013

16. O'Flaherty E and Kaye J: TOX defines a conserved subfamily of HMG-box proteins. BMC Genomics 4: 13, 2003.

17. Yuan SH, Qiu Z and Ghosh A: TOX3 regulates calcium-dependent transcription in neurons. Proc Natl Acad Sci USA 106: 2909-2914, 2009.

18. Dittmer S, Kovacs Z, Yuan SH, Siszler G, Kögl M, Summer H, Geerts A, Golz S, Shioda T and Methner A: TOX3 is a neuronal survival factor that induces transcription depending on the presence of CITED1 or phosphorylated CREB in the transcriptionally active complex. J Cell Sci 124: 252-260, 2011.

19. Xi L, Feber A, Gupta V, Wu M, Bergemann AD, Landreneau RJ, Litle VR, Pennathur A, Luketich JD and Godfrey TE: Whole genome exon arrays identify differential expression of alternatively spliced, cancer-related genes in lung cancer. Nucleic Acids Res 36: 6535-6547, 2008.

20. Tesserma M, Yingling CM, Grimes MJ, Thomas CL, Liu Y, Leng S, Joste N and Belinsky SA: Differential epigenetic regulation of TOX subfamily high mobility group box genes in lung and breast cancers. PLoS One 7: e34850, 2012

21. Zhang X, Zhu H, Wu X, Wang M, Gu D, Gong W, Xu Z, Tan Y, Gong Y, Zhou J, et al: A genetic polymorphism in TOX3 is associated with survival of gastric cancer in a Chinese population. PLoS One 8: e72186, 2013

22. Fasching PA, Pharoah PD, Cox A, Nevanlinna H, Bojesen SE, Karn T, Broeks A, van Leeuwen FE, van't Veer LJ, Udo R, et al: The role of genetic breast cancer susceptibility variants as prognostic factors. Hum Mol Genet 21: 3926-3939, 2012.
23. Gudmundsdottir ET, Barkardottir RB, Arason A, Gunnarsson H, Amundadottir LT, Agnarsson BA, Johannsson OT and Reynisdottir I: The risk allele of SNP rs3803662 and the mRNA level of its closest genes TOX3 and LOC643714 predict adverse outcome for breast cancer patients. BMC Cancer 12: 621, 2012.

24. Riaz M, Berns EM, Sieuwerts AM, Ruigrok-Ritstier K, de Weerd V, Groenewoud A, Uitterlinden AG, Look MP, Klijn JG, Sleijfer S, et al: Correlation of breast cancer susceptibility loci with patient characteristics, metastasis-free survival, and mRNA expression of the nearest genes. Breast Cancer Res Treat 133: 843-851, 2012

25. Garcia-Closas M and Chanock S: Genetic susceptibility loci for breast cancer by estrogen receptor status. Clin Cancer Res 14: 8000-8009, 2008.

26. Reeh M, Bockhorn M, Görgens D, Vieth M, Hoffmann T, Simon R, Izbicki JR, Sauter G, Schumacher U and Anders M: Presence of the coxsackievirus and adenovirus receptor (CAR) in human neoplasms: a multitumour array analysis. Br J Cancer 109: 1848-1858, 2013

27. Lien HC, Lu YS, Cheng AL, Chang WC, Jeng YM, Kuo YH, Huang CS, Chang KJ and Yao YT: Differential expression of glucocorticoid receptor in human breast tissues and related neoplasms. J Pathol 209: 317-327, 2006.

28. Arocho A, Chen B, Ladanyi M and Pan Q: Validation of the 2-DeltaDeltaCt calculation as an alternate method of data analysis for quantitative PCR of BCR-ABL P210 transcripts. Diagn Mol Pathol 15: 56-61, 2006.

29. Fernandez-Navarro P, Pita G, Santamariña C, Moreno MP, Vidal C, Miranda-García J, Ascunce N, Casanova F, Collado-García F, Herráez B, et al: Association analysis between breast cancer genetic variants and mammographic density in a large population-based study (Determinants of Density in Mammographies in Spain) identifies susceptibility loci in TOX3 gene. Eur J Cancer 49: 474-481, 2013.

30. Shan J, Dsouza SP, Bakhru S, Al-Azwani EK, Ascierto ML, Sastry KS, Bedri S, Kizhakayil D, Aigha II, Malek J, et al: TNRC9 downregulates BRCA1 expression and promotes breast cancer aggressiveness. Cancer Res 73: 2840-2849, 2013.

31. Smid M, Wang Y, Klijn JG, Sieuwerts AM, Zhang Y, Atkins D, Martens JW and Foekens JA: Genes associated with breast cancer metastatic to bone. J Clin Oncol 24: 2261-2267, 2006

32. Nordard SH, Johansen FE, Alnaes GI, Naume B, Børresen-Dale AL and Kristensen VN: Genes harbouring susceptibility SNPs are differentially expressed in the breast cancer subtypes. Breast Cancer Res 9: 113, 2007.

33. O'Brien KM, Cole SR, Engel LS, Bensen JT, Poole C, Herring AH and Millikan RC: Breast cancer subtypes and previously established genetic risk factors: a Bayesian approach. Cancer Epidemiol Biomarkers Prev 23: 84-97, 2014. 